\title{
The Service Quality of Online Group-On Companies in Vietnam (A Lesson for Developing Countries)
}

\author{
Dr. Van Ha Nguyen ${ }^{1}$, ,* \\ ${ }^{1}$ Faculty of Business Administration, Orleans University, Orleans, France \\ ${ }^{2}$ Faculty of Business Administration, Banking Academy, Hanoi, Vietnam
}

\begin{abstract}
In the world of increasing competition, most of enterprises will confront certain difficulties on the way of creating their competitive advantage. Online group-on companies in Vietnam are no exceptions; they are supposed to ceaselessly exert themselves in order to bring about the highest customer satisfaction. It helps ensure that the business will not only survive but also grow in the market.

The purpose of the research is "Assessing the service quality of Group-on companies in Vietnam" using qualitative and quantitative method, including a survey period on 204 customers having used the group-on service, direct and in-depth interview with 15 customers. The research is also based on the international database, the E-service model qual (2009) and applying SPSS software to analyzing the research findings.

The research results indicate that the key factors affecting group-buying service quality in Vietnam include: empathy, reliability, information and website acting. Among them, empathy is the strongest effective component.
\end{abstract}

Key words: group-on, group-buying, service quality, Vietnam

\section{Introduction}

Online shopping platforms are growing in number in the world. Online sales and marketing have evolved rapidly in recent years with diversified models such as general shopping websites, group buying, etc. Since group buying first began in the United State in 2008, online group buying spread to Vietnam in 2010, making an underground river to field of electronic commerce in the country.

Thanks to the advantages of internet, online group-buying becomes popular. According to Rezabakhsh et al (2006), "central of idea of online group-buying is aggregation of geographically dispersed consumer purchasing power from all over the countries that have a common interest in a certain product and come together on groupbuying sites to get price discounts". In this increasingly competitive world, companies find it more difficult to bring competitive advantages, and as a part of business world, group purchasing companies in Vietnam have to find the way to keep alive, thrived and developed and make constant efforts to keep their customers satisfied.

This research aims at assessing service quality of group-buying's service in Vietnam through both quantitative and qualitative methods including a customer survey 204 group buying customers, in-depth interviews with 15 customers and draws on international statistic databases, the proposed scales for measuring eservice qual (2009) and uses SPSS 19.0 for analyzing collected data.

The research results indicate that the key factors affecting group-buying service quality in Vietnam include: empathy, reliability, information and website acting. Among them, empathy is the strongest effective component

\section{Overview of Group-Buying}

Group buying has existed in marketplaces for several decades. Erdogmus and Cicek (2011) mentioned that there are two different types of online group buying systems: dynamic pricing and stable pricing. In the dynamic pricing type, the discount prices can be changed basing on the price-quantity tables defined by the sellers. The second type of the online group buying, stable pricing: "the seller offers a certain product/ service at a large discount price, but the price is static, it does not get lower as the number of the buyers increases" (Erdogmus \& Cicek, 2011). Nevertheless, the discount price is only applied when the total number of the buyers who buy the 
deal is greater than the predetermined limit of the minimum required number of buyers. The second type is more popular in Vietnam than the first one.

The first group buying site was founded in 1998, mobshop.com. Shortly after mobshop.com established, the volume of other sites akin established in the US and UK as letbuyit.com, e.conomy.com, ... These sites have similar characteristic of various product offers Except that the price of product categories are not fixed and "volatile", providers will offer a certain amount of time, in that period depending on the amount of people participating, providers will give lower purchase price to various levels following the number of participants.

Beside their strength and advantages, the lack of creativity and they are not really clarity, simplicity, ease of use and attract users as well as provider. Until 2008, the U.S.site Groupon launched was born with simplicity and convenience. An impressive success sparked a trend of group buying model. Only 7 months after establishment, group buying had interest income in 2009 was \$ 100 million, consumer income in 2012 was \$ 760 million. After receiving \$ 135 million investment from DST (Digital sky technologies), groupon's value has hit a record $\$ 1.35$ billion. While other seniors like Twitter needs to 3 years, Facebook needs to 2 years to reach $\$ 1$ billion in value.

Many people believe that Groupon is not a form of e-commerce's development but in fact, Groupon's model combines between e-commerce and advertising. The ultimate goal is not merely Groupon selling coupons, but more important is to promote the brand, brand promotion for suppliers and provide the advantages of marketing.

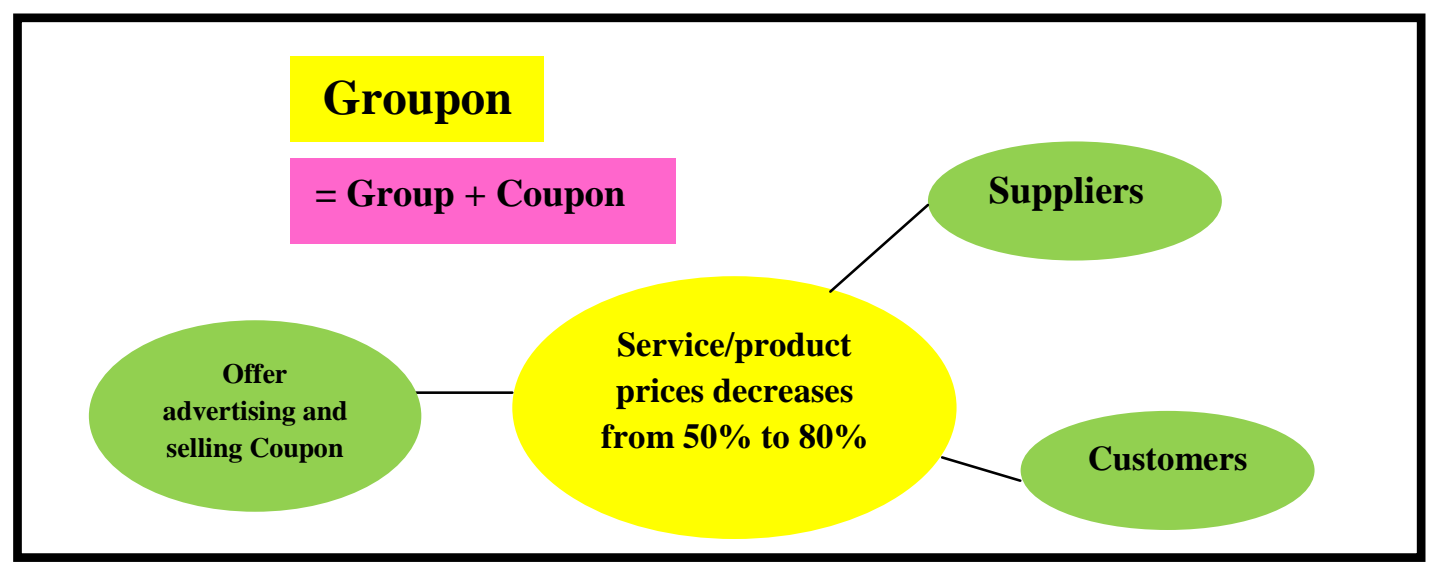

Fig. 1: Groupon model

Source: Collect by author from theory group buying model

\section{Vietnam's Group Buying Market}

In Vietnam, according to electronic information Maskonline online group buying spread to Vietnam in 2010. June, 2010, phagia.com appeared officially, marking an underground river in the realm of Group buying market in Vietnam. Consecutive months later, many other group buying sites were born to compete each other. Late 2011, according to statistics of the nhommua.com, dealcuatui.com, hotdeal.vn, muachung.vn and cungmua.com were leading the market. In particular, in terms of reported revenue, accounting for $36.07 \%$ page, nhommua.com market share is 225586 billion. In the second place is hotdeal.vn with 167068 billion, accounting for 26.54\% market share. Followed by the site muacchung.vn with 91213 billion, accounting for $14.31 \%$ market share. And forth is cungmua.com to 86617 billion, accounting for $13.61 \%$ market share.

Empirical studies of group buying in the U.S., in the development processes, this kind of business model in Vietnam also has certain advantages, namely the acceptance of users. As more people use internet to find goods and services, they can be influenced by their peers to adopt certain behaviors, follow trends, and/or purchase items. A large number of people buy products/services at the promotion time even if they don't really need them. However, starting from the ground up as e-commerce market in Vietnam are still toddlers so this type of business faces many difficulties.

First of all, two age-old problems: payment and delivery. Paying method plays a very important role in group buying model for both parties: sellers and buyers. In Vietnam, following groupon model, majority of 
service providers focus on growth in merchandise, promotion services and delivery methods using pre-collected on the spot.

One other big difference is the level of credibility of the seller in Vietnam is not as high as in the U.S, Japan,... So when customers use coupon, especially in service sector, the staffs do not give thoughtful care to customers. In some cases, customers also are afraid of shopping trap, if the number of participants is not enough transactions as seller's requirement and the service producer is not refundable which was paid in advance, they may have to buy other items that they do not want to buy or buy at higher prices.

Another aspect of the transaction is security. This is a common problem of all groupon models in the world, not only in Vietnam. If the serial number is improvisation, the enterprises will lose lots of time and effort to be able to immediately authenticate with the service producer when they receive the coupon from the customer's hands.

\section{Online Service Quality}

Yang (2001) considered service quality as an important factor to decide the success of online retail business because it influences to consumers' online shopping experiences. If online shoppers don't believe in shopping and handling charges, over 60 prevent of them will exit before completing the buying transaction. For instance, incompleted product information(e.g. missing links and non-working buttons) leads to customer frustration and in turn to existing. Parasuraman et al. (2002) defined online service quality as the extent to which a website facilitates efficient and effective shopping purchasing, and delivery. We can recognize that it includes broadly all phrases of a customer's interactions.

As we can recognize, these scales just focus on evaluating website quality such as design, usage and performance. It lacks of information about service attributes completely, in addition, website quality is just a small part in the service quality chain of group buying model. Group buying must pay attention to other attributes to satisfy customers besides website quality. Parasuraman et al. (2005) also developed an e-recovery service quality scale as long as E-S-QUAL named E-RecS-QUAL as a subscale for problem resolution with three dimensions: Responsiveness, compensation and contact. From that time E-S-Qual and E-RecS-QUAL become an instrument to use popularly, because of their strong effects on customer satisfaction.

In summary, E-service QUAL model was chosen as the research model for this research, here is fairly complete set of scales and general. This research will measure service quality of group buying's market in Vietnam by totally eight dimensions which are shown as below:

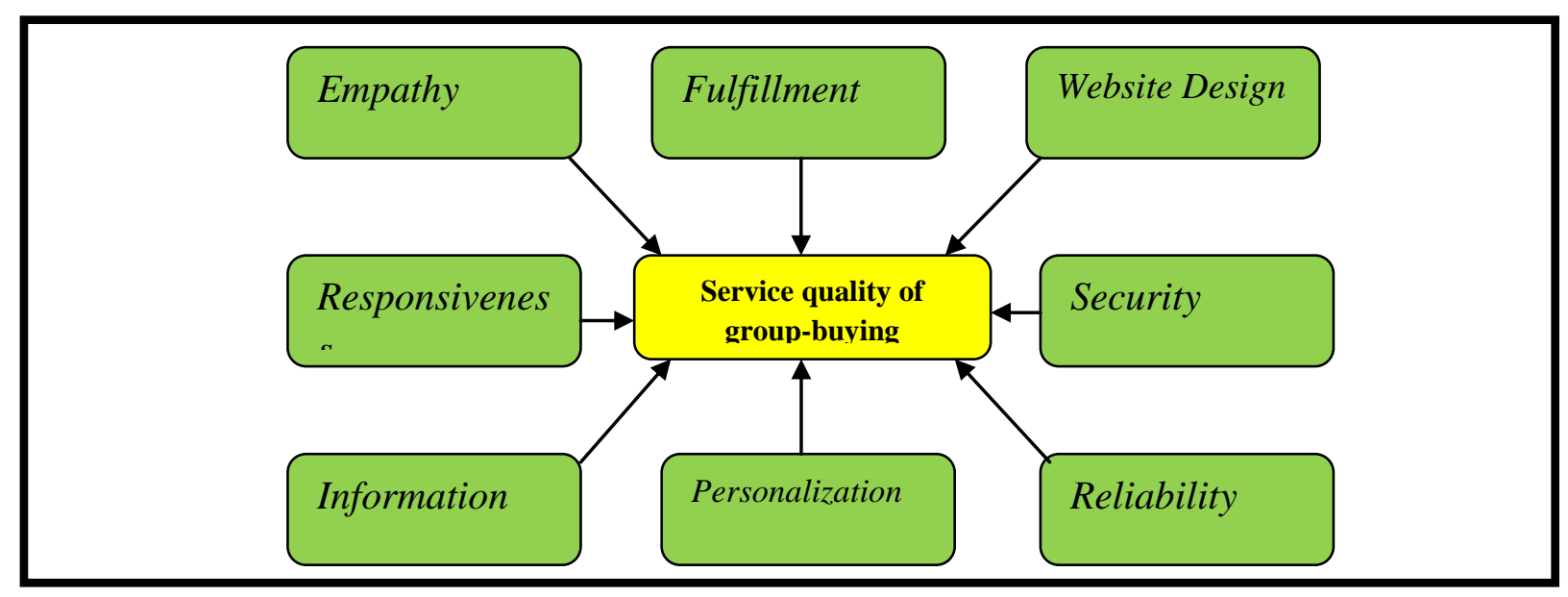

Fig. 2: Proposed scale for measuring service quality of group buying in Vietnam 


\section{Assessing service quality of Group-buying service model in Vietnam}

Preliminary research phase includes 3 steps: qualitative interview, designing questionnaire, and pretesting survey and amending questionnaire. Formal study phase includes 3 steps: collecting formal data, data processing, proposing solutions to enhance service quality. From the results of qualitative research: website design, reliability, responsiveness, security, improvement, communication and empathy are seven factors that affected to service quality of group buying

Questionnaire sample: The questionnaire used the Likert scale with five-point scale as: strongly disagree, disagree, neutral, agree, strongly disagree. In this research, author will conduct survey in Hanoi city, Danang city, and Hochiminh city. Collecting and processing information, testing scales, analyzing components, defining regression equation which shows influence of components on dependent variable. From there, author gives proposing solutions to enhance service quality.

\section{DESIGNING SAMPLE}

Due to general sample is too big and it will be difficult to define the exactly quantity. Defining sample by statistic method cannot perform with time limits and cost limits.

Sample in this research is taken by convenient method. Questionnaire is used as a tool collecting information and it will issue directly or use google document. To anticipate, 270 questionnaires are issued to make sure that when rejecting some invalid questionnaire, author has still had enough size of sample.

After collecting sampling survey completely, author carries out encoding, entering, processing data. Data is analyzed and tested by SPSS 19.0.

After entering data, author uses SPSS to design table of frequency for all variable to check all unusual value as wrong entered data. After that, Use Find command to check and correct.

Total questionnaires issue is 270 , total questionnaires gather is 220 , the questionnaire which can use after cleaning is 204 (ratio: $75.56 \%$ ). As the result, we came to the following conclusion: satisfy the condition to carry out the next steps.

\section{ENCODING DATA}

TABLE I: Table encoding quantitative variable

\begin{tabular}{|c|c|c|c|}
\hline SCALE & $\begin{array}{l}\text { CODE OF } \\
\text { VARIABLE } \\
\end{array}$ & CONTENTS & NUMBER \\
\hline \multirow{5}{*}{ 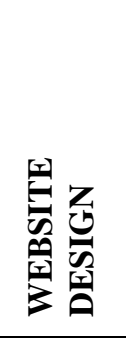 } & tk1 & List of utility of website is organized clearly & \multirow[t]{4}{*}{5} \\
\hline & tk2 & Interface of website is easy to use & \\
\hline & tk3 & Illustrated present image is attractive and beautiful & \\
\hline & tk4 & Place an order through website easily & \\
\hline & tk5 & Speed of download the website's directory is quick and exact & \\
\hline \multirow{8}{*}{ 氞 } & tc1 & Illustrated image is exactly, no misunderstanding & \multirow[t]{8}{*}{9} \\
\hline & tc2 & Website is steady, less error system & \\
\hline & tc3 & Basic price on website is real price on the market & \\
\hline & tc4 & Website confirms order online service exactly & \\
\hline & tc5 & Websites delivery as exactly as order & \\
\hline & tc6 & Product/service quality is similar to statement & \\
\hline & tc7 & Customers who use voucher is treated fairly as who pay in cash & \\
\hline & tc8 & Websites compensate for you when the product/service quality is not & \\
\hline
\end{tabular}




\begin{tabular}{|c|c|c|c|}
\hline & & really good as agreement & \\
\hline & tc9 & Websites make promotion when they promise & \\
\hline \multirow{5}{*}{ 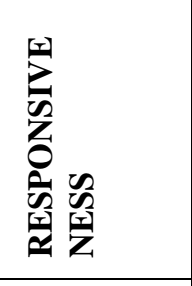 } & ph1 & Contact information is sufficient and validity & \multirow[t]{5}{*}{5} \\
\hline & $\mathrm{ph} 2$ & Website resolve breakdown as exactly as beginning commitment & \\
\hline & ph3 & Your order is confirmed quickly & \\
\hline & $\mathrm{ph} 4$ & Customer care feedback as exactly as appointment & \\
\hline & ph5 & Customer care resolve problem quickly & \\
\hline \multirow{4}{*}{ 䆓 } & bm1 & Financial information is security carefully & \multirow[t]{4}{*}{4} \\
\hline & $\mathrm{bm} 2$ & Personal information is security carefully & \\
\hline & bm3 & Website is a trademark which get the belief of security & \\
\hline & $\mathrm{bm} 4$ & There are a policy to commit protecting security personal information & \\
\hline \multirow{8}{*}{ 空 } & hth1 & There are lots of products/services for you to make option & \multirow[t]{8}{*}{8} \\
\hline & hth2 & You can adjust the process of buying product & \\
\hline & hth3 & Delivering on time & \\
\hline & hth4 & You are informed several hours ago before delivering & \\
\hline & hth5 & Time from placing an order to delivery is quickly & \\
\hline & hth6 & You can change the received place without informing & \\
\hline & hth7 & The process of purchasing is smooth & \\
\hline & hth8 & There are a map to the place where customer can receive product/service & \\
\hline \multirow{3}{*}{ 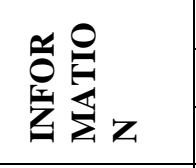 } & thtin1 & Website always have new products/service everyday & \multirow[t]{3}{*}{3} \\
\hline & thtin2 & The left products/services and the purchasing time are updated exactly & \\
\hline & thtin3 & Exactly information of product/service & \\
\hline \multirow{3}{*}{$\sum_{i=1}^{\mathbb{Z}}$} & dc1 & $\begin{array}{l}\text { After delivering, they contact with you to make sure the product/service } \\
\text { which you get, is similar to describing }\end{array}$ & \multirow[t]{3}{*}{3} \\
\hline & $\mathrm{dc} 2$ & The problem you have, they resolve them with friendly attitude & \\
\hline & dc3 & Website's staff is always polite and courtenous with you & \\
\hline \multirow{2}{*}{ 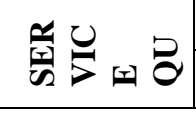 } & cldv1 & Are you satisfied with attitude of staff's website? & \multirow[t]{2}{*}{2} \\
\hline & $\operatorname{cldv} 2$ & In general, service quality of website is as good as expectation & \\
\hline \multicolumn{3}{|l|}{ TOTAL } & 39 \\
\hline
\end{tabular}

\section{DESCRIBING SURVEY SAMPLE}

Among 204 interviewees, there are 67 men, ratio is 32.8\%. There are 137 women, ratio is twice than men. In fact, the people who often use website are women.

Students/pupils occupy the highest ratio with $69.6 \%$. Besides, office staffs occupy rather highly with $21.1 \%$

Due to limited times, ratio of distributive using times is not equal. People who use under 5 times occupy $57.4 \%$. People who use from 5-10 times occupy $25 \%$ and above 10 times occupy $17.6 \%$. However, there is still enough significant to carry out statistical analysis with quantity above.

This classification has a quite good distribution. Occupation of nhommua.com and cungmua.com rather resembles turnover market of website (34.8\% compares with $36.07 \%$ of nhommua.com and $14.7 \%$ compares with $13.61 \%$ of cungmua.com, according to statistics at the end of 2011). 


\section{Testing standard distribution}

Testing standard distribution of variables by seeing frequency distribution of sample as well as Skewness and Kurtosis (Hair et al, 1995). If Skewness and Kurtosis lie in $+/-$, they are good. If they lie in $+/-2$, they are accepted to carry out statistics.

\section{The first evaluating scale reliability}

Hth1 and dc1 are rejected due to coefficient of general variable less than 0.3. Group website design has Cronach's Alpha coefficient less than 0.6 but they have contiguous value (0.575). And this is one of the important parts in the researches before, so author decides to remain it.

\section{The second evaluating scale reliability}

After rejecting hth1 and dc1, author carries out testing and analyzing the second scale towards fulfillment and empathy to ensure that the left variable can get necessary criteria level.

After rejecting variable, Coefficient of Cronback Alpha of fulfillment or Empathy is above 0.6 and all variable have interrelation - total above 0.3 . So satisfy conditions to continue next steps.

\section{Factor analysis}

This research topic uses principle components and Varimax to find the components which express for variable. Parameters need take notice in component analysis: Barlett's testing, KMO (Kaiser-Meyer-Olkin), Kaiser criterion, Communalities, Variance explained criteria, Factor loading

\section{Analyzing components in each scale in the suggestion model}

Researcher conducts component analysis for each scale in the supposed model with aim to clear unsuitable variables before putting in general analysis.

The result shows that KMO coefficient and Barlett's test are satisfactory (KMO $>0.5$, sig. $=0.000)$. Total extracted variance is often more than 50\%, except "Responsiveness" scale (47.640\%). However, this is not too big difference and this is the first analysis, so research decides to remain this component.

\section{Analyzing components with independent variable}

After rejecting hth1, dc1, hth4, hth7 in the analysis step before, all the independent variable in EFA component analysis to find out the last data structure. For this reason, author decides to reject variable gradually to ensure controlling the change better and cut down risk from the beginning.

From the data beginning, through $13^{\text {th }}$ analysis times, 22 variables will be remained.

\section{Analyzing components with dependent variable}

Using the method of taking the principal components with Varimax rotation and suppress absolute values less than 0.3. KMO and Bartlett's testing show that KMO coefficient is 0.500 with significance level is 0.000 . This shows that EFA analysis is suitable.

Checking Communalities table, we see that the values lie in permitted range (more than 0.2) with value of both variable is 0.739 . The result of analyzing cited a component with the cited total variance is $73.900 \%$.

Both of variables are satisfy the condition. So we finish process of component analysis to dependent variable. This component calls "Service quality".

\section{Regression analysis}

Researcher performs linear regressive analysis aim to test linear connection between independent variable and dependent variable. Confirm specifically weighted of each component. To use as fundamental for giving proposals to enhance service quality of group buying at the present. $\beta_{\mathrm{n}}$

Coefficients need to know when using regression analysis: Peta Coefficient, Confirm coefficient $\mathbf{R}^{2} \mathbf{R}^{2} \beta_{0}$ 
In this regression analysis, there are 7 independent variables put in analysis including: Reliability, Delivery, Commitment, Website acting, Sympathy and information and 1 dependent variable is service quality. Mean value of observed variables belongs to each component above is use to regression analysis.

Representative value in the model as following:

- $\mathrm{BM}=\operatorname{mean}(\mathrm{bm} 1, \mathrm{bm} 2, \mathrm{bm} 3, \mathrm{bm} 4)$

- $\mathrm{TC}=\operatorname{mean}(\mathrm{tc} 1, \mathrm{tc} 3, \mathrm{tc} 6, \mathrm{tc} 7)$

- $\mathrm{GH}=\operatorname{mean}($ hth3,hth5,hth6)

- $\quad \mathrm{TT}=\operatorname{mean}($ thtin1,thtin2)

- $\quad \mathrm{C}=\operatorname{mean}(\mathrm{dc} 2, \mathrm{dc} 3)$

- $\quad \mathrm{TTW}=\operatorname{mean}(\mathrm{tk} 4, \mathrm{tk} 5)$

- $\quad$ CLDV $=$ mean $(\operatorname{cldv} 1, \operatorname{cldv} 2)$

With TC, BM, GH, TT, ĐC,TTW are the sympols which corresponde with independent variables and service quality.

Basic regression equation following:

$$
\mathrm{CLDV}=\beta_{0}+\beta_{2} \mathrm{xBM}+\beta_{1} \mathrm{xTC}+\beta_{3} \mathrm{xGH}+\beta_{6} \mathrm{xTT}+\beta_{7} \mathrm{xĐC}+\beta_{5} \mathrm{xTTW}+\varepsilon
$$

After regression analysis, adjusted $\mathrm{R}^{2}$ is 0.404 , it means that independent variable in the model can explain $40.4 \%$ service quality variable. To conclude, independent variable's effect on dependent variable in the model, we can test the regression hypothesis in the next part.

\section{Checking essential infringed assumptions}

A regression model has $\mathrm{R}^{2}$ with high adjustment, it hasn't still conclude anything if supposition of regression method following is not appropriate

\section{Supposition of appropriateness of model}

F testing which uses in table of variance analysis is a testing method to show linear relation between dependent variable and independent variable with supposition $\mathrm{H}_{0}$ :

$\beta_{1}=\beta_{2}=\beta_{3}=\beta_{4}=\beta_{5}=\beta_{6}=0$

From that result, we can see F testing has very minor Sig. (0.000), so we can reject $\mathrm{H}_{0}$, it indicates that multiple linear regression is appropriative with data and it is useful.

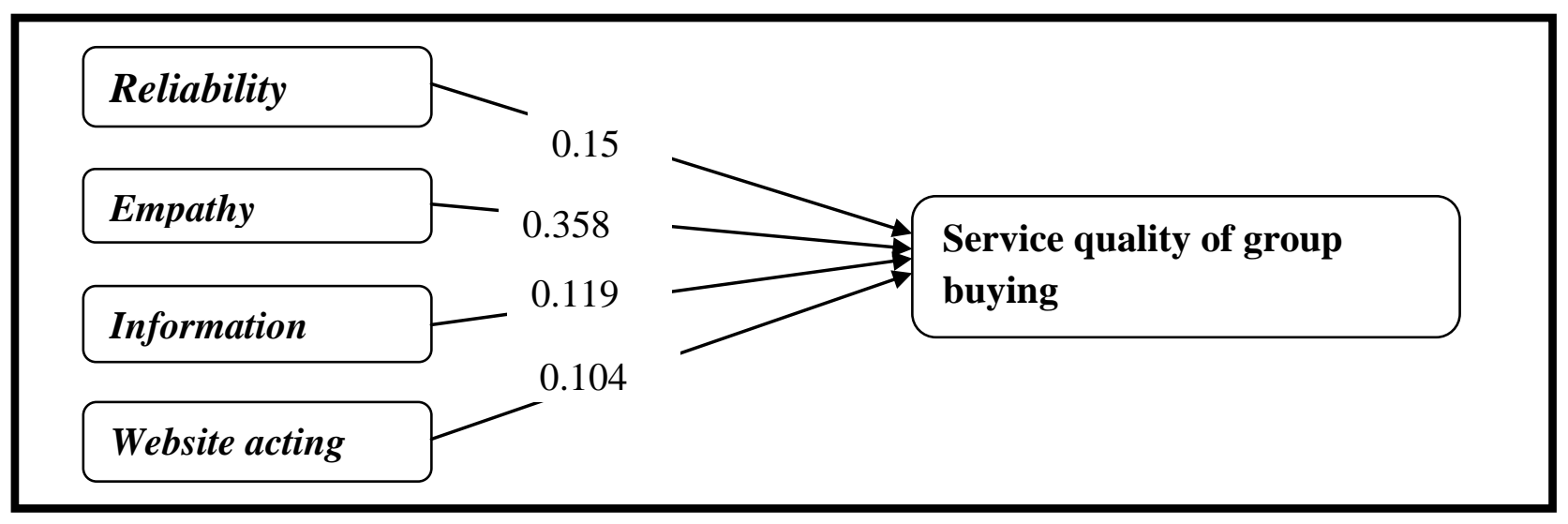

Fig. 3: Completed research model 


\section{Conclusion}

Lean on the result of regression analysis and all supposition is to satisfy evaluating service quality of group buying model is concluded:

\section{Regression equation: Service quality $=0.15 \times$ reliability $+0.358 \times$ Empathy $+0.119 \times$ information $+0.104 x$ interaction website}

Comments: From the beginning model includes 8 components. Through analyzing, there are 6 factors left in the regression model to evaluate effects on service quality. There are 4 components, which have strong effects on service quality is "Reliability", "Empathy", "information", "Website acting". Among them, "Empathy" is the strongest effective component with coefficient regression is 0.358 .

"Security" component, it doesn't have lots effects on service quality. "Security" includes security of finance information, personal information, prestigious of website and policy of commitment with customers. At the present, Payment method of group buying in Vietnam is cash. Besides that, the main customer of group buying is students who don't take notice much on security. That is a part of reason why security doesn't consider as an important part in service quality.

"Delivery" component, it doesn't affect remarkable on service quality. "Delivery" includes: Delivery on time, delivery quickly, customers can change the place delivery. This can explain by characteristic of group buying. Transaction happens when they get enough necessary quantity from customers. That is the reason why, delaying from shipping to receive often happens. One more thing, vouchers often have expiry date, so customers don't have much complaint when delivery delays.

Finally it could be conclude that there is a significant positive relationship between business performance and 4 dimensions of service quality - reliability, empathy, information and interaction website to enhancing service quality of group-buying in Vietnam market.

\section{Reference}

[1] Hoàng Trọng, Chu Nguyễn Mộng Ngọc. (2005). Data analysis with SPSS1, 2. Published by Thong Ke Publisher.

[2] Dave Chaffey and PR Smith (2008), eMarketing eXcellence: Planning and optimizing your digital marketing,Butterworth-Heinemann is an imprint of Elsevier Linacre House, Jordan Hill, Oxford OX2 8DP, UK30 Corporate Drive, Burlington, MA 01803, USA; First published 2002, Copyright @ 2008, Dave Chaffey and PR Smith. All rights reserved

[3] Kassim, N. M., \& Abdullar, N. A. (2008). "Customer loyalty in e-commercial settings: An empirical study", Electronic market, 18(3), 275-290.

http://dx.doi.org/10.1080/10196780802265843

[4] Kauffman, R. J., Lai, H., \& Lin, H. C. (2010). "Customer adoption of group-buying auctions: an experimental study", Information technology and management, 11(4), 191-211.

http://dx.doi.org/10.1007/s10799-010-0068-z

[5] B. Yoo, N. Donthu. (2001). "Developing a scale to measure perceived quality of an Internet shopping site (SITEQUAL)”, Quarterly Journal of Electronic Commerce, Vol. 2 No. 1, 31-46.

[6] Hongxiu Li, Reima Suomi. (2009). “A Proposed Scale for Measuring E-service Quality”, International Journal of uand e-Service: Science and Technology, Vol. 2 No. 1.

[7] Hongxiu Li, Liu Yong, Suomi Reima(2009). "Measurement of e-service quality: an empirical study on online travel service", 17th European Conference on Information Systems.

[8] Lorena Batagan, Adrian Pocovnicu, Sergiu Capisizu. (2009). "E- Service Quality Management", Journal of applied Quantitative Methods, Vol. 4 No. 3, 272-281.

[9] Parasuraman, V.A. Zeithaml, and A. Malhotra. (2005). "E-S-QUAL: A multiple-item scale for assessing electronic service quality", Journal of Service Research, Vol. 7 No. 3, 213-234.

http://dx.doi.org/10.1177/1094670504271156 